\title{
Revisiting "Success" and "Failure" of Marine Protected Areas: A Conservation Scientist Perspective
}

OPEN ACCESS

Edited by:

Trevor John Willis,

University of Portsmouth,

United Kingdom

Reviewed by:

Graham Edgar

University of Tasmania, Australia

Bryce Stewart,

University of York, United Kingdom

${ }^{*}$ Correspondence:

Sylvaine Giakoumi

sylvaine.giakoumi1@gmail.com

Specialty section:

This article was submitted to

Marine Conservation and

Sustainability,

a section of the journal

Frontiers in Marine Science

Received: 27 December 2017 Accepted: 11 June 2018 Published: 29 June 2018

Citation:

Giakoumi S, McGowan J, Mills M, Beger M, Bustamante RH, Charles A, Christie P, Fox M,

Garcia-Borboroglu P, Gelcich S, Guidetti P, Mackelworth P, Maina JM, McCook L, Micheli F, Morgan LE,

Mumby PJ, Reyes LM, White A, Grorud-Colvert $K$ and Possingham HP (2018) Revisiting "Success" and

"Failure" of Marine Protected Areas: A Conservation Scientist Perspective.

Front. Mar. Sci. 5:223.

doi: 10.3389/fmars.2018.00223

\author{
Sylvaine Giakoumi ${ }^{1,2 *}$, Jennifer McGowan ${ }^{1}$, Morena Mills ${ }^{1,3}$, Maria Beger ${ }^{1,4}$, \\ Rodrigo H. Bustamante ${ }^{5}$, Anthony Charles ${ }^{6}$, Patrick Christie ${ }^{7}$, Matthew Fox ${ }^{8}$, \\ Pablo Garcia-Borboroglu ${ }^{9,10,11}$, Stefan Gelcich ${ }^{12}$, Paolo Guidetti ${ }^{2,13}$, Peter Mackelworth ${ }^{14,15}$, \\ Joseph M. Maina ${ }^{1}$, Laurence McCook ${ }^{8,16,17}$, Fiorenza Micheli ${ }^{18}$, Lance E. Morgan ${ }^{19}$, \\ Peter J. Mumby ${ }^{20}$, Laura M. Reyes ${ }^{10,21}$, Alan White ${ }^{22,23}$, Kirsten Grorud-Colvert ${ }^{24}$ and \\ Hugh P. Possingham ${ }^{1,25}$
}

${ }^{1}$ ARC Centre of Excellence for Environmental Decisions, School of Biological Sciences, The University of Queensland, Brisbane, QLD, Australia, ${ }^{2}$ FRE 3729 ECOMERS, Centre National de la Recherche Scientifique, Université Côte d'Azur, Nice, France, ${ }^{3}$ Department of Life Sciences, Imperial College London, Silwood Park, United Kingdom, ${ }^{4}$ School of Biological Sciences, Faculty of Biological Sciences, School of Biological Sciences, University of Leeds, Leeds, United Kingdom, ${ }^{5}$ CSIRO Oceans and Atmosphere Research, Ecosciences Precinct, Brisbane, QLD, Australia, ${ }^{6}$ School of the Environment and School of Business, Saint Mary's University, Halifax, NS, Canada, ${ }^{7}$ School of Marine and Environmental Affairs and Jackson School of International Studies, University of Washington, Seattle, WA, United States, ${ }^{8}$ Conservation International, Bali, Indonesia, ${ }^{9}$ CONICET Argentina, Puerto Madryn, Argentina, ${ }^{10}$ Global Penguin Society, Puerto Madryn, Argentina, ${ }^{11}$ Department of Biology, University of Washington, Seattle, WA, United States, ${ }^{12}$ Facultad de CienciasBiologicas, Center of Applied Ecology and Sustainability and Centro de Conservacion Marina, Pontificia Universidad Catolica de Chile, Santiago, Chile, ${ }^{13}$ National Interuniversity Consortium of Marine Sciences (CoNISMa), Rome, Italy, ${ }^{14}$ Blue World Institute of Marine Research and Conservation, Veli Lošinj, Croatia, ${ }^{15}$ Department of Biodiversity, FAMNIT, University of Primorska, Koper, Slovenia, ${ }^{16}$ ARC Centre of Excellence for Coral Reef Studies, James Cook University, Townsville, QLD, Australia, ${ }^{17}$ South China Sea Institute of Oceanology, Chinese Academy of Sciences, Guangzhou, China, ${ }^{18}$ Hopkins Matine Station and Stanford Center for Ocean Solutions, Stanford University, Pacific Grove, CA, United States, ${ }^{19}$ Marine Conservation Institute, Glen Ellen, CA, United States, ${ }^{20}$ Marine Spatial Ecology Lab, School of Biological Sciences, University of Queensland, Brisbane, QLD, Australia, ${ }^{21}$ Universidad Nacional de la Patagonia San Juan Bosco, Puerto Madryn, Argentina, ${ }^{22}$ The Nature Conservancy, Asia Pacific Program, Honolulu, HI, United States, ${ }^{23}$ USAID Sustainable Ecosystems Advanced Project, Tetra Tech ARD, Jakarta, Indonesia, ${ }^{24}$ Department of Integrative Biology, Oregon State University, Corvallis, OR, United States,

${ }^{25}$ The Nature Conservancy, Arlington, VA, United States

Marine protected areas (MPAs) form the cornerstone of marine conservation. Identifying which factors contribute to their success or failure is crucial considering the international conservation targets for 2020 and the limited funds generally available for marine conservation. We identified common factors of success and/or failure of MPA effectiveness using peer-reviewed publications and first-hand expert knowledge for 27 case studies around the world. We found that stakeholder engagement was considered to be the most important factor affecting MPA success, and equally, its absence, was the most important factor influencing failure. Conversely, while some factors were identified as critical for success, their absence was not considered a driver of failure, and vice versa. This mismatch provided the impetus for considering these factors more critically. Bearing in mind that most MPAs have multiple objectives, including non-biological, this highlights the need for the development and adoption of standardized effectiveness metrics, besides biological considerations, to measure factors contributing to the success or failure of MPAs to reach their objectives. Considering our conclusions, we suggest the development of specific protocols for the assessment of stakeholder engagement, the role of leadership, the capacity of enforcement and compliance with MPAs objectives. Moreover, factors defining the success and failure of MPAs should be assessed not 
only by technical experts and the relevant authorities, but also by other stakeholder groups whose compliance is critical for the successful functioning of an MPA. These factors should be considered along with appropriate ecological, social, and economic data and then incorporated into adaptive management to improve MPA effectiveness.

Keywords: conservation scientists, effectiveness assessment, failure, marine protected areas, stakeholder engagement, success

\section{INTRODUCTION}

More than 15,000 marine protected areas (MPAs) cover roughly $7 \%$ of the world's marine environment (Lubchenco and GrorudColvert, 2015; UNEP-WCMC IUCN, 2017). Scientific evidence shows that MPAs can produce ecological, economic, and social benefits under appropriate design and management conditions (Ban et al., 2012; PISCO UNS, 2016). Comparative studies across marine regions have enabled us to explore common factors contributing to MPA success (e.g., Charles and Wilson, 2009; Edgar et al., 2014). However, assessments of the factors that result in the failure of MPAs to achieve their objectives using information from many regions are far less common (but see Gill et al., 2017). The emphasis on success and achievement may allow us to overlook the importance of failure for learning and development. MPAs are expensive ventures absorbing much of the scarce resources allocated to marine conservation. Thus, identifying practices that ensure MPA effectiveness is a major issue (Pendleton et al., 2018).

Herein, 21 conservation scientists and practitioners (the authors of this paper) used their first-hand knowledge of 27 MPA case studies from around the world (Figure 1, Appendix S1, Table S1.1). These case studies were used to critically consider how success and failure are defined and measured when assessing MPA effectiveness. In addition, key factors driving MPA success and failure were identified.

\section{DEFINING MPA SUCCESS AND FAILURE}

Given our case-studies span many countries, socio-ecological systems, and biogeographic regions, we needed to establish a common definition by which to benchmark the success or failure of an MPA. The general English language dictionaries define success as "the accomplishment of an aim or purpose." Using that definition, an MPA was considered a success if it accomplished its objectives. Conversely, failure was defined as "not accomplishing an aim or purpose." Thus, an MPA would be a failure if its implementation and/or management were insufficient, inappropriate or neglected. The last would be the case of the so called "paper parks" (Agardy et al., 2011; Scianna et al., 2015). An important challenge is how to assess success or failure when multiple objectives are involved. The aims of MPAs often include ecological, social, economic, cultural, and institutional objectives (Fox et al., 2012). In many cases, planning for multiple objectives concurrently demands trade-offs in achievement across social, economic, and ecological domains (Beger et al., 2015). Thus, in practice, most MPAs have aspects of both success and failure (Christie, 2004). Here, we focus on success or failure in achieving ecological outcomes, because evidence is more abundant for assessing ecological rather than other objectives (Gill et al., 2017).

\section{MEASURING MPA SUCCESS AND FAILURE}

MPA effectiveness, in ecological terms, is commonly measured by comparing values of ecological or biological measures (e.g., sizes of organisms, density and biomass of fish assemblages, species richness, live cover of benthic organisms) in MPAs and adjacent unprotected areas and/or before and after an MPA is established. However, the appropriate rigor of the empirical design for such evaluations of the ecological effectiveness is often lacking (Ferraro and Hanauer, 2014). Thus, our assessments of ecological success, while considering available published evidence, reflect our perspectives based on first-hand experience and expert knowledge (Table S1.2). Acknowledging the fact that MPA effectiveness is not static, this assessment corresponds to a specific time period for which we had data and/or personal experience. This period does not necessarily correspond to the initial stage of the MPA establishment but also to later post-establishment stages which vary across our case studies depending on the age of each MPA.

For each case study, we considered 23 factors that were identified through group discussions and a literature review, as those commonly attributed to MPA "success" and "failure" (Table S1.1). For each case study, five factors were ranked based on their importance for the success or failure of the case study (for more information see Appendix S1).

\section{ASSESSING MPA SUCCESS AND FAILURE}

On aggregating the individual rankings, most factors indicating success were found to also point to failure; i.e., when the presence of a factor was considered to lead to success, its absence led to failure (Figure 2, Table S1.3). Overall, the factors viewed as principal drivers of success and failure of MPA effectiveness were related to contextual factors, such as governance and socioeconomic characteristics, rather than the design attributes, such as the MPA size.

Stakeholder engagement was consistently selected as the most important factor affecting MPA success; its absence was most often linked to failure. Other factors that were reported as crucial for success, and their absence as drivers of failure, included: surveillance, leadership, political will, and the existence of sanctioning and conflict resolution mechanisms. Interestingly, 


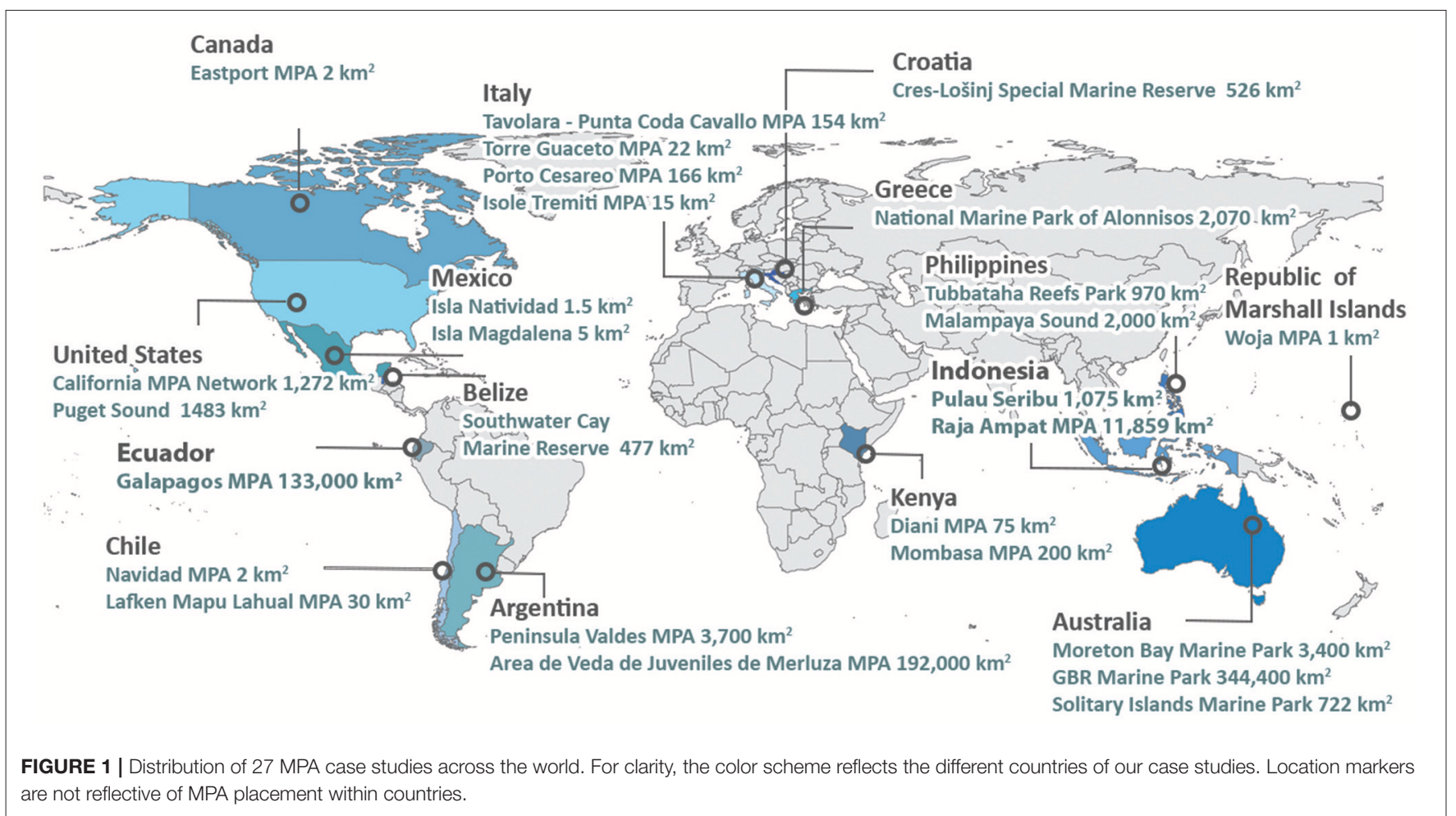

are not reflective of MPA placement within countries.

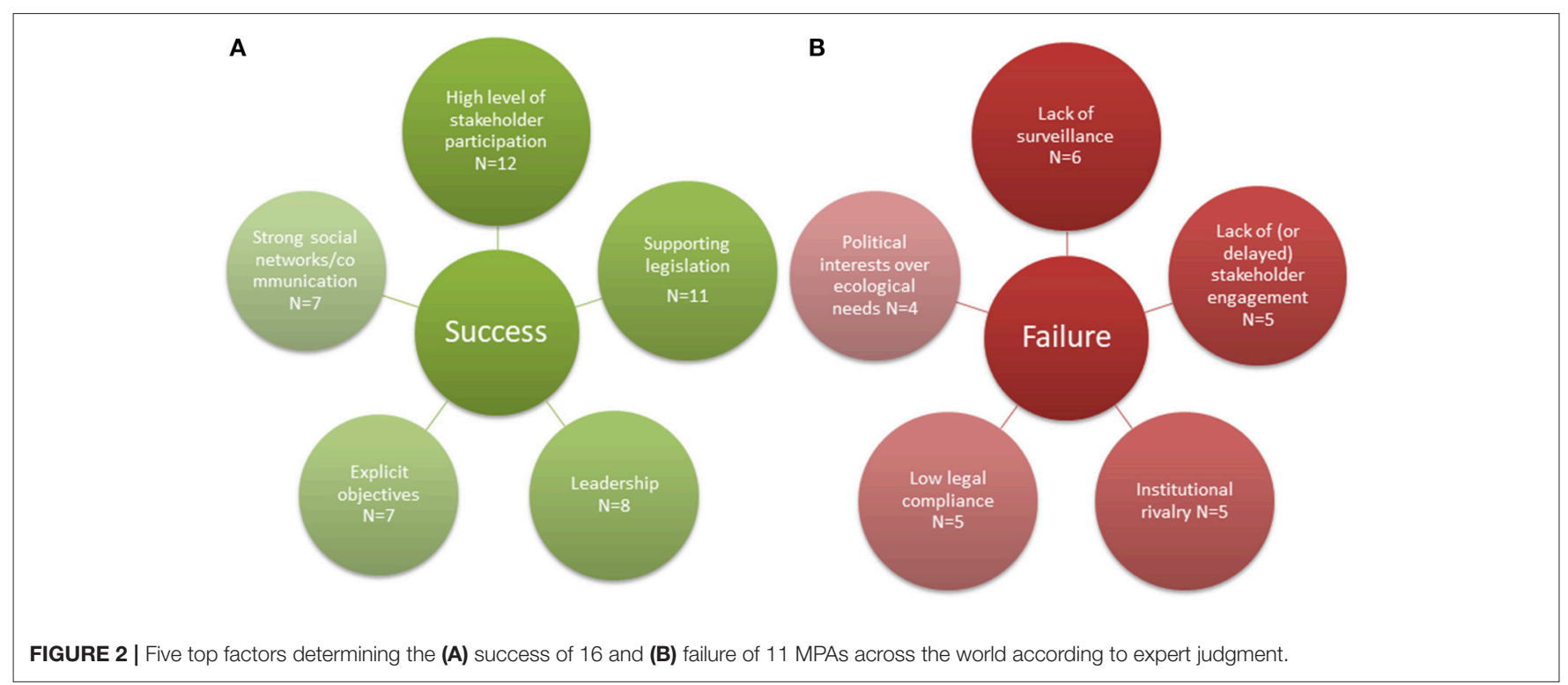

whereas some factors were identified as critical for success, their absence was not identified as a driver of failure (Table S1.3). Those factors include setting clear objectives, strong scientific engagement throughout the planning and implementation stages, and the existence of clearly delineated MPA boundaries. The existence of explicit objectives (i.e., well-defined overarching qualitative objectives such as protection of endangered species or habitats, fisheries enhancement, or food security) was selected as one of the most important factors defining success. Yet, its absence was never identified amongst the most important factors contributing to MPA failure. This mismatch may originate from disparities between the scientific principles of MPA design, on the one hand, and practical realities of MPAs, on the other. Scientific literature often recommends that MPA goals and objectives should be clearly defined, compatible with one another, and account for inherent uncertainty (Rossiter and Levine, 2014). In practice, however, the absence of explicit objectives may not lead to failure, but may facilitate broader acceptance by a range of stakeholders, each of which may have a different set of objectives with respect to their interests. 
Conversely, certain factors contributed to failure, but their presence was never selected as crucial for success (Table S1.3). Those factors include: legal compliance, effective MPA size, and the correct identification of key stakeholder groups during the planning process. A lack of compliance, and consequently illegal activities within the area, were commonly noted as causing the failure of MPAs to achieve ecological objectives. Logically, compliance should have been identified as an indispensable driver of success, but in our activity, it seems to have been taken for granted and was not highlighted as a factor in driving success. This could potentially be attributed to the implicit assumption that it is inconceivable to have a successful MPA without compliance when assessing drivers.

\section{RECOMMENDATIONS FOR FUTURE RESEARCH}

Looking to the future, we have two major recommendations. First, we need to develop standardized measures to link the range of factors influencing success and failure to MPA effectiveness. Monitoring and evaluation of MPA effectiveness are most often limited to assessments of biological and ecological metrics, such as fish biomass (e.g., Sala and Giakoumi, 2018). Meanwhile, crucial social factors identified herein (Figure 2), such as stakeholder engagement, are rarely measured in a systematic way. Currently, there are very few studies demonstrating the direct relationships between participatory governance and improved ecological metrics (Stafford, 2018, but see Di Franco et al., 2016). Thus, the adoption of standardized metrics for social factors is a prerequisite for identifying how these factors truly affect MPA effectiveness and for developing guidance to decision-makers on how to improve MPA planning. More specifically, based on our collective experience, we suggest the development of protocols for the assessment of the following factors:

\section{Stakeholder Engagement}

Stakeholder engagement is a dynamic process that needs to be dialogue-based and include feedback mechanisms that allow stakeholders to assess their engagement. Social auditing, defined as a process that enables an organization to assess its performance in relation to society's requirements and expectations (Gao and Zhang, 2006), could be a valuable approach to engage stakeholders in marine conservation and promote co-operation. Ideally, all stakeholder groups should be involved in the process; in practice, however, this is rarely possible. Therefore, specific groups, whose compliance is crucial for MPA effectiveness, e.g., small-scale fishing co-operatives and local government (Beger et al., 2004; Di Franco et al., 2016), should be targeted.

\section{Leadership}

Conservation success stories are often related to a key individual, a "leader," who made things happen. Recently, there has been a shift from the individual leader at the top, to the process of leadership, which can occur throughout an organization and is not restricted to one person or group with a formal role (Schultz and Fazey, 2009). The design of processes that promote and evaluate leadership in MPAs within the framework of adaptive management is crucial for evaluating the MPA performance.

\section{Enforcement and Compliance}

Effectiveness also depends on how the MPA authority influences the behavior of marine users through enforcement and/or compliance. Enforcement and compliance are linked and need to be monitored. Indices to monitor enforcement (e.g., hours of surveillance) are straightforward. The assessment of compliance is more complex and could be based on modeling and gametheoretic approaches, then validated by available empirical data (see Keane et al., 2008). Such approaches could assist MPA managers to optimize enforcement strategies and encourage compliance.

In our exercise, we defined success and failure in terms of achieving ecological outcomes, but we recognize that there are a range of possible objectives that can be assessed (e.g., improvements in wellbeing). Empirical studies around the factors that lead to the success and failure of particular objectives of MPAs (e.g., biodiversity conservation or fisheries enhancement) are needed. These studies should be based on clear experimental designs and be sufficiently replicated to obtain statistically reliable results. Rigorous empirical studies would then allow the provision of more specific recommendations around the design and management of MPAs planned for different objectives. Furthermore, we recognize that the results presented herein reflect the opinion of a restricted number of conservation scientists. Exploring whether our findings apply to the wider conservation community is a necessary next step.

Secondly, within a given context and for a specific objective, assessments of the drivers leading to MPA success and failure should be conducted by multiple stakeholders (e.g., different groups of commercial and recreational fishers, tourism operators, conservation scientists) and compared across groups. The importance of factors defining success and failure may differ significantly among stakeholder groups as each group has an inherent bias toward particular MPA objectives. The factors defining success and/or failure that are shared widely across the various stakeholder groups should be a priority for scientific research and investment of conservation efforts in the specific context. Although various sources of bias and uncertainty are associated with expert knowledge elicitation, the benefits of incorporating such knowledge into decision-making can be substantial (Martin et al., 2012). Furthermore, this process should be repeated through time to avoid a static view of success and failure, as these likely change over time. Iterative stakeholder assessments accompanied with updated ecological, social, and economic assessments of MPA performance based on empirical data should be incorporated into adaptive management. More effective MPA design, implementation, and management can then be achieved by building on success and learning from failure. Some of these lessons may be transferable between MPAs; however, some others may not as the importance of the factors determining MPA effectiveness depends on the spatial scale of the MPA (Ban et al., 2017; Giakoumi et al., 2017) as well as the 
socio-cultural, political, and legislative context in which the MPA is established (Gill et al., 2017).

\section{AUTHOR CONTRIBUTIONS}

SG coordinated this effort and wrote the first draft of the paper, JM and MM produced the figures, all authors provided questionnaire input, edited and contributed with text.

\section{ACKNOWLEDGMENTS}

We thank all participants of the workshop Marine protected areas: overcoming barriers to successful implementation held at the 2014 Pew Fellows Annual Meeting for discussions. We also

\section{REFERENCES}

Agardy, T., Notarbartolo di Sciara, G., and Christie, P. (2011). Mind the gap: addressing the shortcomings of marine protected areas through large scale marine spatial planning. Mar. Policy 35, 226-232. doi: 10.1016/j.marpol.2010.10.006

Ban, N., Cinner, J., Adams, V., Mills, M., Almany, G., Ban, S., et al. (2012). Recasting shortfalls of marine protected areas as opportunities through adaptive management. Aquat. Conserv. 22, 262-271. doi: 10.1002/aqc.2224

Ban, N. C., Davies, T. E., Aguilera, S. E., Brooks, C., Cox, M., Epstein, G., et al. (2017). Social and ecological effectiveness of large marine protected areas. Global Environ. Chang. 43, 82-91. doi: 10.1016/j.gloenvcha.2017.01.003

Beger, M., Harborne, A. R., Dacles, T. P., Solandt, J.-L., and Ledesma, G. L. (2004). A framework of lessons learnt from community-based marine reserves and its effectiveness in guiding a new coastal management initiative in the Philippines. Environ. Manag. 34, 786-801. doi: 10.1007/s00267-004-0149-Z

Beger, M., McGowan, J., Treml, E. A., Green, A. L., White, A. T., Wolff, N. H., et al. (2015). Integrating regional conservation priorities for multiple objectives into national policy. Nat. Commun. 6:8208. doi: 10.1038/ncomms9208

Charles, A., and Wilson, L. (2009). Human dimensions of marine protected areas. ICES J. Mar. Sci. 66, 6-15. doi: 10.1093/icesjms/fsn182

Christie, P. (2004). Marine protected areas as biological successes and social failures in Southeast Asia. Am. Fish. Soc. Symp. 42, 155-164.

Di Franco, A., Thiriet, P., Di Carlo, G., Dimitriadis, C., Francour, P., Gutiérrez, N. L., et al. (2016). Five key attributes can increase marine protected areas performance for small-scale fisheries management. Sci. Rep. 6:38135. doi: $10.1038 /$ srep 38135

Edgar, G. J., Stuart-Smith, R. D., Willis, T. J., Kininmonth, S., Baker, S. C., Banks, S., et al. (2014). Global conservation outcomes depend on marine protected areas with five key features. Nature 506, 216-220. doi: 10.1038/nature13022

Ferraro, P. J., and Hanauer, M. M. (2014). Advances in measuring the environmental and social impacts of environmental programs. Аnnu. Rev. Environ. Resour. 39, 495-517. doi: 10.1146/annurev-environ-101813013230

Fox, H. E., Mascia, M. B., Basurto, X., Costa, A., Glew, L., Heinemann, D., et al. (2012). Re-examining the science of marine protected areas: linking knowledge to action. Conserv. Lett. 5, 1-10. doi: 10.1111/j.1755-263X.2011.00207.x

Gao, S. S., and Zhang, J. J. (2006). Stakeholder engagement, social auditing and corporate sustainability. Bus. Process Manag. J. 6, 722-740. doi: 10.1108/14637150610710891

Giakoumi, S., Scianna, C., Plass-Johnson, J., Micheli, F., Grorud-Colvert, K., Thiriet, P., et al. (2017). Ecological effects of full and partial protection in the crowded Mediterranean Sea: a regional meta-analysis. Sci. Rep. 7:8940. doi: 10.1038/s41598-017-08850-w

Gill, D. A., Mascia, M. B., Ahmadia, G. N., Glew, L., Lester, S. E., et al. (2017). Capacity shortfalls hinder the performance of marine protected areas globally. Nature 543, 665-669. doi: 10.1038/nature21708 thank Polita Glynn for assisting in the workshop organization. SG, JM, and MM were supported by ARC CEED, University of Queensland funding. RB, PC, PG-B, SGe, LMcC, FM, PM, AW, and HP were supported by The Pew Fellows Program in Marine Conservation. AC was supported by funding from SSHRC and NSERC, Canada. LMcC was supported in part by a President's International Visiting Professor Fellowship (2016VEA025) from the Chinese Academy of Sciences.

\section{SUPPLEMENTARY MATERIAL}

The Supplementary Material for this article can be found online at: https://www.frontiersin.org/articles/10.3389/fmars. 2018.00223/full\#supplementary-material

Keane, A., Jones, J. P. G., Edwards-Jones, G., and Milner-Gulland, E. J. (2008). The sleeping policeman: understanding issues of enforcement and compliance in conservation. Anim. Conserv. 11, 75-82. doi: 10.1111/j.1469-1795.2008.00170.x

Lubchenco, J., and Grorud-Colvert, K. (2015). Making waves: the science and politics of ocean protection. Science 350, 382-383. doi: 10.1126/science.aad5443

Martin, T. G., Burgman, M. A., Fidler, F., Kuhnert, P. M., Low-Choy, S., McBride, M., et al. (2012). Eliciting expert knowledge in conservation science. Conserv. Biol. 26, 29-38. doi: 10.1111/j.1523-1739.2011.01806.x

Pendleton, L., Ahmadia, G. N., Browman, H. I., Thurstan, R. H., Kaplan, D. M., and Bartolino, V. (2018). Debating the effectiveness of marine protected areas. ICES J. Mar. Sci. 75, 1156-1159. doi: 10.1093/icesjms/fsx154

PISCO and UNS (2016). The science of marine protected areas (3rd Edition, Mediterranean). Partnership for Interdisciplinary Studies of Coastal Oceans and University of Nice Sophia Antipolis. 22. Available online at: www.piscoweb.org (Accessed January 25, 2017).

Rossiter, J. S., and Levine, A. (2014). What makes a "successful" marine protected area? The unique context of Hawaii's fish replenishment areas. Mar. Policy 44, 196-203. doi: 10.1016/j.marpol.2013.08.022

Sala, E., and Giakoumi, S. (2018). No-take marine reserves are the most effective protected areas in the ocean. ICES J. Mar. Sci. 75, 1166-1168. doi: 10.1093/icesjms/fsx059

Schultz, L., and Fazey, I. (2009). "Effective leadership for adaptive management," in Adaptive Environmental Management: A Practitioners Guide, eds C. Allan, G. Stankey (Dordrecht: Springer), 295-303.

Scianna, C., Niccolini, F., Gaines, S. D., and Guidetti, P. (2015). 'Organization Science': a new prospective to assess marine protected areas effectiveness. Ocean Coast. Manag. 116, 443-448. doi: 10.1016/j.ocecoaman.2015.09.005

Stafford, R. (2018). Lack of evidence that governance structures provide real ecological benefits in marine protected areas. Ocean Coast. Manag. 152, 57-61. doi: 10.1016/j.ocecoaman.2017.11.013

UNEP-WCMC and IUCN (2017). Marine Protected Planet [On-line], [December, 2017]. Cambridge: UNEP-WCMC and IUCN. Available online at: www. protectedplanet.net

Conflict of Interest Statement: The authors declare that the research was conducted in the absence of any commercial or financial relationships that could be construed as a potential conflict of interest.

Copyright (C) 2018 Giakoumi, McGowan, Mills, Beger, Bustamante, Charles, Christie, Fox, Garcia-Borboroglu, Gelcich, Guidetti, Mackelworth, Maina, McCook, Micheli, Morgan, Mumby, Reyes, White, Grorud-Colvert and Possingham. This is an openaccess article distributed under the terms of the Creative Commons Attribution License (CC BY). The use, distribution or reproduction in other forums is permitted, provided the original author(s) and the copyright owner(s) are credited and that the original publication in this journal is cited, in accordance with accepted academic practice. No use, distribution or reproduction is permitted which does not comply with these terms. 